\title{
MANeJo DE Conyza bonariensis RESISTENTE Ao GlyPHOSATE: Coberturas de Inverno e Herbicidas em Pré-Semeadura da SOJA ${ }^{1}$
}

\author{
Management of Glyphosate Resistant Conyza bonariensis: Winter Cover Crops and Herbicides \\ in Soybean Pre-Seeding
}

LAMEGO, F.P. ${ }^{2}$, KASPARY, T.E. ${ }^{3}$, RUCHEL, Q. ${ }^{4}$, GALLON, M. ${ }^{5}$, BASSO, C.J. ${ }^{6}$ e SANTI, A.L. ${ }^{6}$

\begin{abstract}
RESUMO - Conyza bonariensis tornou-se a principal planta daninha da cultura da soja no Sul do Brasil, em decorrência da evolução para resistência ao herbicida glyphosate. O objetivo deste trabalho foi avaliar o efeito de diferentes coberturas de inverno e da associação de manejo de dessecação pré-semeadura da soja, visando ao controle de $C$. bonariensis resistente ao glyphosate. Um experimento foi conduzido em campo, na safra 2010/2011. Os tratamentos foram conduzidos em esquema de parcelas subdivididas, em que as coberturas de inverno foram alocadas nas parcelas principais: aveia-preta, nabo, ervilhaca, azevém, trigo e pousio. Nas subparcelas, foram alocados os tratamentos de manejo de dessecação pré-semeadura da soja: glyphosate (720 g e.a ha-1), glyphosate $\left(720 \mathrm{~g} \mathrm{e.a} \mathrm{ha}^{-1}\right)+2$,4-D (1.050 g e.a ha-1), glyphosate $\left(720 \mathrm{~g}\right.$ e.a ha $\left.{ }^{-1}\right)+2,4-\mathrm{D}(1.050 \mathrm{~g}$ e.a ha-1)/paraquat $(200 \mathrm{~g}$ i.a ha-1) + diuron (100 g i.a ha-1), glyphosate (720 g e.a ha-1) + chlorimuron-ethyl (80 g i.a ha-1), glyphosate $\left(720 \mathrm{~g} \mathrm{e} \mathrm{e} \mathrm{ha}^{-1}\right)+$ chlorimuron-ethyl $\left(80 \mathrm{~g}^{\text {i.a ha }} \mathrm{h}^{-1}\right) /$ paraquat $\left(200 \mathrm{~g}\right.$ i.a ha $\left.{ }^{-1}\right)+$ diuron (100 g i.a ha $^{-1}$ ) e roçada. O nabo foi a espécie de cobertura que produziu o maior volume de massa seca durante o inverno, enquanto a ervilhaca foi a que apresentou maior efeito supressor sobre a germinação e o desenvolvimento inicial de $C$. bonariensis. Associações de glyphosate com 2,4-D ou chlorimuron-ethyl, seguidas da aplicação sequencial de paraquat + diuron, causaram maior redução na infestação de $C$. bonariensis.
\end{abstract}

Palavras-chave: buva, resistência, herbicida, pousio.

\begin{abstract}
Conyza bonariensis became the main weed in soybean crop in Southern Brazil, as a consequence of the evolution of resistance to the herbicide glyphosate. The objective of this work was to evaluate the effect of different winter cover crops and the association of burn-down herbicides on the control of glyphosate-resistant $\boldsymbol{C}$. bonariensis. A field experiment was conducted in the 2010/2011 season. The treatments were arranged in a split-plot scheme, with the winter cover crops lopsided oat, radish, common vetch, Italian ryegrass, wheat, and fallow in the main plots, and in the subplots, the following burn-down treatments: glyphosate (720 g e.a ha-1), glyphosate

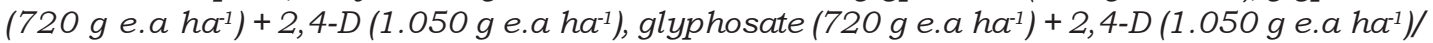

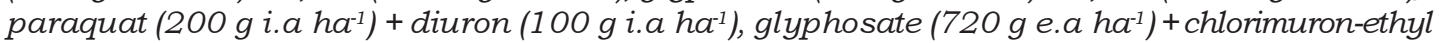
$\left(80 \mathrm{~g}\right.$ i.a ha-1) , glyphosate $\left(720 \mathrm{~g} \mathrm{e.a} \mathrm{ha^{-1 } )}+\right.$ chlorimuron-ethyl $(80 \mathrm{~g}$ i.a ha-1)/paraquat $\left(200 \mathrm{~g} \mathrm{i.a} \mathrm{ha}^{-1}\right)+$ diuron (100 $\mathrm{g}$ i.a ha $\left.\mathrm{h}^{-1}\right)$ and mowing. Radish was the cover crop species that produced the highest amount of shoot dry mass during the winter season, while common vetch had the highest suppressive effect on germination and initial development of C. bonariensis. Associations of glyphosate with 2, 4-D or chlorimuron-ethyl, followed by the sequential application of paraquat + diuron, caused the highest reductions in $\mathbf{C}$. bonariensis infestation.
\end{abstract}

Keywords: hairy fleabane, resistance, herbicide, fallow treatment.

1 Recebido para publicação em 20.9.2012 e aprovado em 26.1.2013.

2 Professora, Dra., Dep. de Ciências Agronômicas e Ambientais, UFSM/CESNORS, Linha Sete de Setembro s/n BR 386 Km 40 , 98400-000 Frederico Westphalen-RS, <fabilamego@yahoo.com.br>; ${ }^{3}$ Engo-Agr ${ }^{0}$, Mestrando do Programa de Pós-graduação em Agronomia - Agricultura e Ambiente (PPGAAA), Universidade Federal de Santa Maria - UFSM/CESNORS, <tiagokaspary@hotmail.com>; ${ }^{4}$ Eng $^{\mathrm{a}}$-Agr ${ }^{\mathrm{a}}$., Mestranda do Programa de Pós-Graduação em Fitossanidade (PPGFs), Universidade Federal de Pelotas - UFPel, <queli.ruchel@yahoo.com.br>; ${ }^{5}$ Graduando do Curso de Agronomia, UFSM/CESNORS, <mtgallon90@yahoo.com.br>; ${ }^{6}$ Professor, Dr., Dep. de Ciências Agronômicas e Ambientais, UFSM/CESNORS.

Planta Daninha, Viçosa-MG, v. 31, n. 2, p. 433-442, 2013 


\section{INTRODUÇÃO}

O aumento gradativo da infestação da espécie daninha buva (Conyza bonariensis) nas áreas agrícolas cultivadas com soja na região Sul do Brasil tornou esta uma das principais plantas daninhas da cultura. Esse fato é decorrente da alta adaptabilidade dessa planta aos sistemas de produção e da evolução de biótipos resistentes ao herbicida glyphosate. Desse modo, a buva tem ocasionado graves prejuízos às lavouras de soja, exigindo dos agricultores a adoção de métodos alternativos de controle. Como consequência, há aumento nos custos de produção.

C. bonariensis, pertencente à família Asteraceae, é uma espécie autógama e originária da América do Sul (Kissman \& Groth, 1999). Essa espécie apresenta ciclo anual e caracteriza-se por ser muito prolifera, podendo produzir mais de 200 mil sementes viáveis em uma única planta (Bhowmik \& Bekech, 1993). Suas sementes germinam no outono/inverno, com ciclo adentrando o verão (Kissman \& Groth, 1999).

A infestação por buva em áreas de cultivo, especialmente aquelas ocupadas com soja, deve-se ao fato de sua boa adaptabilidade aos sistemas conservacionistas de solo, como é o caso do sistema de semeadura direta e do cultivo minimo, amplamente utilizados em lavouras no Sul do País. Essa característica, aliada à autopolinização, à grande quantidade de sementes produzidas e à facilidade de dispersão destas, que podem atingir distâncias superiores a 100 metros (Dauer et al., 2006), caracteriza a buva como uma planta daninha de alta adaptabilidade ecológica. Desse modo, há facilitação para sobrevivência de biótipos resistentes e para a geração de altas infestações, observadas atualmente nas áreas de produção agrícola.

O controle da buva antecedendo a semeadura da soja baseava-se, até pouco tempo, no uso do herbicida glyphosate, amplamente usado em função da expansão da soja geneticamente modificada e resistente a esse herbicida. Essa prática, adotada em larga escala por muitos anos e com aplicações do herbicida mais de uma vez por ano (dessecação da área em pré-semeadura dos cultivos de verão e em pós-emergência na soja transgênica), levou à evolução de biótipos de buva resistentes a esse herbicida. Desse modo, a resistência de buva a glyphosate tem forçado os agricultores a adotar medidas alternativas para reduzir as perdas que ocorrem nas lavouras de soja.

Uma das opções disponíveis dentro de um sistema de manejo integrado de plantas daninhas é a utilização de plantas de cobertura de solo durante o período de outono/inverno, complementada pelo manejo químico com herbicidas alternativos ao glyphosate em pré-semeadura da soja. A população de C. bonariensis resistente ao glyphosate foi maior em áreas mantidas em pousio do que naquelas cultivadas com trigo ou aveia-preta durante o inverno (Paula et al., 2010). Isso porque as plantas de cobertura exerceram efeito supressor sobre a infestante, facilitando seu controle na pré-semeadura da cultura em sucessão.

O efeito da presença da cobertura vegetal e a manutenção de restos vegetais na superfície do solo podem reduzir a emergência e o estabelecimento de plantas daninhas em determinada área, seja através do efeito físico, como também do efeito químico e/ou alelopático, além de proteger o solo da radiação solar e aumentar a eficiência da ciclagem de nutrientes (Oliveira et al., 2001). Nesse sentido, falhas no controle de buva estão associadas ao estádio avançado ou estatura de planta elevada da espécie daninha na ocasião da aplicação do herbicida, possivelmente observadas em áreas mantidas em pousio durante o inverno, bem como à combinação ineficiente dos herbicidas e à resistência ao glyphosate (Vargas et al., 2007).

A cobertura de inverno aliada a um manejo alternativo na dessecação, pela utilização da associação de produtos com o glyphosate, tem proporcionado controle mais satisfatório, uma vez que mecanismos de ação herbicida alternativos ainda controlam buva resistente ao glyphosate. Todavia, estudo conduzido nos Estados Unidos identificou populações de Conyza canadensis com resistência cruzada aos herbicidas inibidores da enzima acetolactato sintase (ALS), devido a três diferentes mutações no gene da enzima (Zheng et al., 2011). 
É importante ressaltar que as coberturas de inverno utilizadas podem ser culturas comerciais, como, por exemplo, trigo, aveiabranca e aveia-preta, dos quais também poderá se obter receita, além do efeito supressor na germinação e emergência de buva. Assim, a avaliação do efeito das coberturas de inverno, aliada ou não a um controle químico mais eficaz, mostra-se como opção no manejo integrado de buva, não só para a cultura da soja, mas para o sistema produtivo como um todo. Espera-se com isso diminuir perdas, aumentar a produtividade e a lucratividade da produção, além de minimizar impactos sobre o meio ambiente e auxiliar no controle da evolução da resistência de $C$. bonariensis aos herbicidas.

O presente trabalho teve por objetivo avaliar o efeito de diferentes coberturas de inverno, associadas ou não a um controle químico pré-semeadura da soja, no manejo de Conyza bonariensis resistente ao herbicida glyphosate.

\section{MATERIAL E MÉTODOS}

O experimento foi conduzido em campo, no município de Jaboticaba-RS, no ano agrícola de 2010/2011. O solo da área caracteriza-se como Latossolo Vermelho distrófico típico (Embrapa, 2006), com as seguintes propriedades fisicas e químicas: argila $=67 \%$; $\mathrm{pH}$ água $=5,6$; indice $\mathrm{SMP}=6,5$; matéria orgânica $=$ $3,1 \%$; fósforo $=10,9 \mathrm{mg} \mathrm{dm}^{-3}$; potássio $=$ $84 \mathrm{mg} \mathrm{dm}^{-3}$; cálcio $=5,3 \mathrm{cmol}_{\mathrm{c}} \mathrm{dm}^{-3}$; magnésio $=5,0 \mathrm{cmol}_{\mathrm{c}} \mathrm{dm}^{-3}$; e enxofre $=10 \mathrm{cmol}_{\mathrm{c}} \mathrm{dm}^{-3}$.

O delineamento experimental foi de blocos casualizados, sendo os tratamentos arranjados em parcela subdividida; as parcelas principais apresentavam dimensões de 4,0 x 96,0 m, onde foram alocadas as coberturas de inverno: trigo (cultivar Quartzo), aveia-preta (Avena strigosa), ervilhaca (Vicia angustifolia), nabo forrageiro (Raphanus spp.), azévem (Lolium multiflorum), bem como o pousio. As subparcelas, com dimensões de 4,0 x 6,0 m, foram constituídas pelos tratamentos de manejo da cobertura pré-semeadura da soja: glyphosate (720 g e.a ha-1); glyphosate $+2,4-\mathrm{D}$ $\left(720\right.$ g e.a ha ${ }^{-1}+1.005$ g e.a ha-1); glyphosate + 2,4-D (720 g e.a ha ${ }^{-1}+1.005$ g e.a ha $\left.^{-1}\right) /$ paraquat + diuron $\left(200+100 \mathrm{~g}\right.$ i.a ha $\left.\mathrm{h}^{-1}\right)$, aplicado na véspera da semeadura; glyphosate + chlorimuron-ethyl (720 g e.a ha ${ }^{-1}+80$ g i.a ha $\left.{ }^{-1}\right)$; glyphosate + chlorimuron-ethyl (720 g e.a ha ${ }^{-1}$ +80 g i.a ha $\left.{ }^{-1}\right) /$ paraquat + diuron $(200+$ $100 \mathrm{~g}_{\text {i. }} \mathrm{h} \mathrm{ha}^{-1}$ ), aplicado na véspera da semeadura; e uma testemunha sem herbicida, onde a massa verde foi manejada com roçadeira.

As coberturas de inverno foram semeadas em 28/5/2010, sendo o trigo e a aveia-preta semeados em linha no espaçamento de $0,17 \mathrm{~m}$, ambos para uma população de 350 plantas $\mathrm{m}^{-2}$. As demais coberturas foram semeadas a lanço, sendo utilizadas para nabo, ervilhaca e azevém as quantidades de 20, 80 e $40 \mathrm{~kg} \mathrm{ha}^{-1}$ de sementes, respectivamente. No pré-florescimento das coberturas de inverno, em área de $0,25 \mathrm{~m}^{2}$, foi colhida a massa verde da parte área e colocada em estufa a $60{ }^{\circ} \mathrm{C}$ até peso constante, para posterior determinação da massa seca da parte aérea, sendo os resultados expressos em tha ${ }^{-1}$.

A aplicação dos tratamentos pré-semeadura bem como a roçada foram realizadas 20 dias antes da semeadura da soja, em 9/10/2010. Para isso, foi utilizado pulverizador costal pressurizado a $\mathrm{CO}_{2}$, com volume de calda de $200 \mathrm{~L} \mathrm{ha}^{-1}$, e barra de aplicação equipada com quatro pontas tipo leque XR 110.02, distanciadas $0,5 \mathrm{~m}$ entre si. As condições de aplicação eram de $22{ }^{\circ} \mathrm{C}$ de temperatura e umidade relativa do ar (UR) de $85 \%$. Para a associação de paraquat + diuron, aplicada no dia 28/10/2010 (véspera da semeadura da soja), as condições ambientais eram de temperatura de $26{ }^{\circ} \mathrm{C}$ e UR de $85 \%$. Vinte dias antes da semeadura da soja, a população de plantas de $C$. bonariensis na área foi determinada (plantas $\mathrm{m}^{-2}$ ), utilizando-se um quadro metálico de $0,25 \mathrm{~m}^{2}$, lançado aleatoriamente, quatro vezes por faixa de cobertura. Também, aos 12 e aos 27 dias após a emergência da soja (DAE), novas avaliações de emergência de C. bonariensis foram feitas, segundo metodologia já descrita.

A soja (cv. BMX Energia) foi semeada no dia 29/10/2010, com espaçamento de 0,45 m entre linhas e densidade de 27 sementes $\mathrm{m}^{-2}$, o que proporcionou população de 25 plantas $\mathrm{m}^{-2}$. A adubação de base utilizada foi de $250 \mathrm{~kg} \mathrm{ha}^{-1}$ da formulação (NPK) 00-18-18, correspondendo a $45 \mathrm{~kg} \mathrm{ha}^{-1}$ de fósforo e $45 \mathrm{~kg} \mathrm{ha}^{-1}$ de potássio. Durante o desenvolvimento da soja, foram 
realizadas intervenções, quando necessárias, referentes ao controle de pragas e doenças. Além disso, foi realizada uma aplicação de glyphosate (900 g e.a ha ${ }^{-1}$ ) aos 18 dias após a emergência (DAE) da soja, para controle das plantas daninhas ocorrentes na área.

A colheita da soja foi realizada manualmente em 13/3/2011, sendo colhidas as quatro fileiras centrais da parcela (área útil de $\left.5,4 \mathrm{~m}^{2}\right)$. A produtividade de grãos $\left(\mathrm{kg} \mathrm{ha}^{-1}\right)$ foi determinada, com teor de umidade corrigido para $13 \%$. Em dez plantas aleatórias da área útil foram determinados a estatura de planta (cm) e os componentes da produtividade (número de legumes por planta, número de grãos por legume e peso de mil grãos).

Os dados obtidos foram submetidos à análise de variância com auxílio de programa estatístico; havendo significância, os tratamentos foram comparados pelo teste de Duncan e, no caso de interação entre os fatores, adotou-se o teste de DMS a 5\% de probabilidade.

\section{RESULTADOS E DISCUSSÃO}

As diferentes espécies avaliadas como plantas de cobertura distinguiram-se quanto à produção de massa vegetal produzida. O nabo forrageiro e a ervilhaca foram aqueles que produziram o maior volume de massa seca, com valores médios de 5,40 e 5,08 tharespectivamente (Tabela 1 ). A quantidade de cobertura vegetal produzida refletiu diretamente em menor infestação de plantas de buva na primeira avaliação realizada, previamente aos tratamentos de dessecação e/ou roçada pré-semeadura da soja, principalmente na área onde havia ervilhaca. Nesse caso, foi observada apenas, na média, 1 planta $\mathrm{m}^{-2} \mathrm{de}$ buva, valor bem inferior ao de 157 plantas $\mathrm{m}^{-2}$, observado na área que permaneceu em pousio durante todo o inverno (Tabela 1).

A presença de cobertura vegetal sobre o solo torna-se de grande valia na redução da emergência e do desenvolvimento das plantas de buva na área, uma vez que as falhas no controle estão associadas, entre outros fatores, ao estádio das plantas por ocasião da aplicação do herbicida. Ressalta-se ainda que as coberturas impedem a incidência direta de luz solar sobre o solo, afetando a germinação de sementes de buva. Resultados obtidos por Bhowmik \& Bekech (1993) demonstram atraso na germinação em até quatro semanas e redução de emergência de plântulas de $80 \%$, inferindo que essa planta daninha necessita de luz para desencadear o processo germinativo.

A ervilhaca, embora tenha apresentado estabelecimento inicial e ciclo de desenvolvimento mais lento, quando comparada às demais espécies de cobertura avaliadas (dados não apresentados), formou uma intensa barreira física, dificultando a germinação e emergência das sementes de buva presentes no banco de sementes do solo da área. De maneira geral, na avaliação de infestação de buva realizada em pré-semeadura da soja, foi possivel constatar que todas as coberturas avaliadas tiveram papel importante na redução da ocorrência da planta daninha quando comparadas ao pousio, com destaque para a cultura da ervilhaca, que reduziu a infestação da daninha em cerca de $98 \%$.

A infestação de buva avaliada após a emergência da soja apresentou interação significativa entre os tratamentos $(\leq 0,05)$. Aos $12 \mathrm{DAE}$, novamente as coberturas utilizadas demonstraram contribuir para a supressão da emergência da buva, todas elas diferindo da área mantida em pousio durante o inverno (Tabela 2). De maneira geral, aos $12 \mathrm{DAE}$, os tratamentos herbicidas envolvendo glyphosate a $720 \mathrm{~g}$ e. a ha-1 associado a 2,4-D a 1.005 g e.a ha- ou chlorimuron-ethyl a

Tabela 1 - Massa seca da parte aérea das coberturas vegetais e infestação de buva (Conyza bonariensis) - pré-dessecação para a semeadura da soja. Jaboticaba-RS, 2010/11

\begin{tabular}{|l|c|c|}
\hline Cobertura vegetal & $\begin{array}{c}\text { Massa seca } \\
\left(\mathrm{t} \mathrm{ha}^{-1}\right)\end{array}$ & $\begin{array}{c}\text { Buva } \\
\left(\text { plantas } \mathrm{m}^{-2}\right)\end{array}$ \\
\hline Pousio & $1,17 \mathrm{e}^{*}$ & $157 \mathrm{a}$ \\
\hline Azevém & $3,86 \mathrm{~d}$ & $6 \mathrm{~b}$ \\
\hline Ervilhaca & $5,08 \mathrm{ab}$ & $1 \mathrm{c}$ \\
\hline Nabo & $5,44 \mathrm{a}$ & $11 \mathrm{~b}$ \\
\hline Trigo & $4,58 \mathrm{bc}$ & $10 \mathrm{~b}$ \\
\hline Aveia-preta & $4,12 \mathrm{~cd}$ & $9 \mathrm{~b}$ \\
\hline CV $(\%)$ & 10,00 & 19,20 \\
\hline
\end{tabular}

* Médias seguidas de mesma letra na coluna não diferem entre si pelo teste de Duncan a $5 \%$ de probabilidade. 
Tabela 2 - Infestação de buva (Conyza bonariensis) (plantas $\mathrm{m}^{-2}$ ) 12 dias após emergência da soja (DAE), cv. BMX Energia, em função de coberturas de inverno e manejo da cobertura vegetal pré-semeadura da soja. Jaboticaba-RS, 2010/11

\begin{tabular}{|c|c|c|c|c|c|c|c|}
\hline \multirow{2}{*}{ Manejo } & \multicolumn{7}{|c|}{ Cobertura de inverno } \\
\hline & $\operatorname{Dose}^{3 /}$ & Pousio & Aveia-preta & Trigo & Nabo & Ervilhaca & Azevém \\
\hline Roçada & - & A $40 a^{*}$ & A $11 \mathrm{bc}$ & A $13 \mathrm{~b}$ & $\mathrm{~A} 0 \mathrm{~d}$ & A $0 \mathrm{~d}$ & A $9 \mathrm{c}$ \\
\hline Gly $^{1 /}$ & 720 & A $42 \mathrm{a}$ & $\mathrm{AB} 9 \mathrm{~b}$ & $\mathrm{AB} 10 \mathrm{~b}$ & $\mathrm{~A} 0 \mathrm{c}$ & $\mathrm{A} 0 \mathrm{c}$ & A $9 \mathrm{~b}$ \\
\hline Gly+2,4-D & $720+1005$ & B $10 \mathrm{a}$ & $\mathrm{CD} 3 \mathrm{~b}$ & B 7 a & $\mathrm{A} 0 \mathrm{~b}$ & $\mathrm{~A} 0 \mathrm{~b}$ & $\mathrm{BC} 3 \mathrm{~b}$ \\
\hline Gly $+2,4-\mathrm{D} /$ paraquat + diuron & $720+1005 / 200+100$ & $\mathrm{C} 4 \mathrm{a}$ & D $1 \mathrm{ab}$ & $\mathrm{C} 2 \mathrm{ab}$ & $\mathrm{A} 0 \mathrm{~b}$ & $\mathrm{~A} 0 \mathrm{~b}$ & $\mathrm{BC} 1 \mathrm{ab}$ \\
\hline $\mathrm{Gly}^{2} \mathrm{Chl}^{2 /}$ & $720+80$ & B $13 \mathrm{a}$ & $\mathrm{BC} 6 \mathrm{~b}$ & C $3 b c$ & $\mathrm{~A} 0 \mathrm{c}$ & $\mathrm{A} 0 \mathrm{c}$ & B $4 \mathrm{~b}$ \\
\hline $\mathrm{Gly}+\mathrm{Chl} /$ paraquat+diuron & $720+80 / 200+100$ & B $13 \mathrm{a}$ & $\mathrm{CD} 3 \mathrm{~b}$ & $\mathrm{C} 1 \mathrm{~b}$ & $\mathrm{~A} 0 \mathrm{~b}$ & $\mathrm{AOb}$ & $\mathrm{COb}$ \\
\hline $\mathrm{CV}(\%)$ & & & & & & & \\
\hline
\end{tabular}

${ }^{1 /}$ glyphosate; ${ }^{2 /}$ chlorimuron-ethyl; ${ }^{2} /$ Dose em g e.a ou g i.a ha ${ }^{-1}$.

* Letras maiúsculas semelhantes na coluna e letras minúsculas semelhantes na linha não diferem entre si pelo teste de DMS a 5\%.

$80 \mathrm{~g}$ i.a ha ${ }^{-1}$, em aplicação única ou complementados pela mistura pré-formulada de paraquat+diuron, apresentaram redução satisfatória e significativa na população de C. bonariensis, quando comparados ao tratamento glyphosate isolado ou roçada (Tabela 2). Resultado semelhante para a associação de glyphosate e 2,4-D no manejo de buva foi obtido por Vargas et al. (2007), que, ao utilizarem 1.005 g e.a ha-1 de 2,4-D sobre biótipos de C. bonariensis resistente e suscetivel ao glyphosate, obtiveram controle que variou de 95 a $100 \%$, respectivamente, 30 dias após a aplicação dos tratamentos. Todavia, plantas mais desenvolvidas, como aquelas que ocorreram na área em pousio, podem não ter sido eficientemente controladas apenas pela associação herbicida empregada no manejo présemeadura. Também, foi observado controle satisfatório de $C$. bonariensis quando utilizado glyphosate $+2,4-D$ ou glyphosate + diuron + paraquat, na pré-semeadura da soja (Paula et al., 2011).

Não foram observadas infestações de buva na soja aos $12 \mathrm{DAE}$, em sucessão a ervilhaca ou nabo forrageiro (Tabela 2). Esse resultado é explicado pela elevada massa vegetal produzida por essas coberturas durante o seu desenvolvimento. Já nas áreas de soja, após azevém e aveia-preta, por exemplo, mesmo quando da associação de glyphosate com 2,4-D, complementada por paraquat+diuron, ainda se observou, em média, 1 planta $\mathrm{m}^{-2}$ de buva aos 12 DAE (Tabela 2). Embora o azevém tenha produzido menor quantidade de cobertura vegetal quando comparado ao nabo (Tabela 1), ou seja, $3,86 \mathrm{t} \mathrm{ha}^{-1}$ contra $5,44 \mathrm{th} \mathrm{h}^{-1}$, respectivamente, é possivel que, juntamente com o efeito físico, tanto o azevém quanto a aveiapreta possam ter contribuído para a supressão da germinação de buva através de algum efeito químico ou alelopático. Balbinot Jr. et al. (2005) observaram redução da ordem de cinco vezes na massa acumulada das plantas daninhas em área com cobertura de azevém, comparada a outra com nabo.

Ressalta-se ainda que o efeito pronunciado do azevém em suprimir a infestação da buva no período de pós-emergência da soja (Tabela 2) pode estar ligado ao fato de ele apresentar alta relação C/N. Desse modo, com a deposição de sua palhada sobre o solo, microrganismos que fazem a decomposição imobilizam nitrogênio mineral do solo. Nesse período, dependendo das exigências nutricionais da planta daninha, esta pode ter seu crescimento e desenvolvimento inibidos devido à deficiência do nutriente (Correa et al., 2006).

As combinações de herbicidas na dessecação pré-semeadura da soja após a constatação de $C$. bonariensis resistente foram significativamente mais eficientes que a utilização isolada de glyphosate (Tabela 2). Este não diferiu estatisticamente apenas da área que foi manejada de forma mecânica (roçada). Entretanto, as associações de glyphosate com 2,4-D e com chlorimuron-ethyl demonstraram grande eficácia no controle da buva. Resultados semelhantes foram observados por Vargas et al. (2007), os quais, avaliando a utilização de herbicidas alternativos em aplicação única sobre plantas de buva resistentes 
ao glyphosate, obtiveram resultados favoráveis para 2,4-D, paraquat, chlorimuron-ethyl, metsulfuron-methyl e paraquat + diuron, da ordem de $100 \%$.

No presente trabalho, os melhores desempenhos foram obtidos onde as associações com glyphosate foram complementadas de forma sequencial, pela mistura formulada de paraquat + diuron, controlando as plantas que sobraram da dessecação anterior, em um intervalo de 20 dias. Assim, houve redução da infestação de buva para próximo de zero em ambas as avaliações (Tabelas 2 e 3). O mesmo foi observado por Oliveira Neto et al. (2010), em que aplicações sequenciais de glyphosate + 2,4-D e, posteriormente, de paraquat + diuron apresentaram controle em torno de 97\% da buva presente na área.

Plantas de $C$. bonariensis, mesmo aquelas suscetiveis ao herbicida glyphosate, em estádios mais avançados de desenvolvimento (superiores a $20 \mathrm{~cm}$ de estatura) podem não ser controladas também pelas associações herbicidas ou até mesmo por aplicações sequenciais. Dessa forma, constata-se a importância de evitar e/ou minimizar a germinação e o desenvolvimento inicial de $C$. bonariensis, sendo as coberturas de inverno uma importante ferramenta para o manejo.

$\mathrm{Na}$ segunda avaliação da infestação de C. bonariensis, realizada aos $27 \mathrm{DAE}$, verificou-se de forma geral redução do número de plantas da espécie daninha por área, principalmente onde foi utilizado o herbicida paraquat + diuron (Tabela 3). Contudo, durante o mesmo período, nos tratamentos roçada e glyphosate isolado sobre a área que teve trigo como cobertura de inverno, ocorreu pequeno incremento no número de buvas. É importante ressaltar que o cultivo de uma cobertura de inverno complementa o manejo da buva na soja, uma vez que, mesmo aos $27 \mathrm{DAE}$ da soja em sucessão ao nabo e a ervilhaca, a área se manteve sem incidência de buva (Tabela 3 ).

Além dos efeitos sobre a germinação e infestação de buva, a qual emerge ainda no inverno e retoma seu desenvolvimento próximo à semeadura da soja, a prática do uso de coberturas de inverno traz uma série de vantagens para conservação do solo, sendo fundamental em áreas de produção leiteira (sobretudo no caso da aveia-preta e do azevém), e, ainda, no caso do trigo, pode ser uma fonte de receita; já o seu cultivo é prática comum na região noroeste do RS.

Em relação às plantas de soja, para a variável estatura de planta avaliada na colheita, observou-se, de forma geral, apenas efeito das coberturas de inverno, não se observando diferenças significativas dos manejos utilizados em pré-semeadura da cultura. Assim, o trigo foi a espécie que influenciou de maneira superior a estatura da soja, enquanto para as demais coberturas não houve diferença significativa (Figura 1). Os resultados divergem daqueles encontrados por Lima et al. (2009), que, ao avaliarem a influência de coberturas vegetais sobre a estatura de plantas da soja, não observaram diferenças entre os tratamentos testados.

Tabela 3 - Infestação de buva (Conyza bonariensis) (plantas $\mathrm{m}^{-2}$ ) 27 dias após emergência da soja (DAE), cv. BMX Energia, em função de coberturas de inverno e manejo da cobertura vegetal pré-semeadura da soja. Jaboticaba-RS, 2010/11

\begin{tabular}{|c|c|c|c|c|c|c|c|}
\hline \multirow{2}{*}{ Manejo } & \multicolumn{7}{|c|}{ Cobertura de inverno } \\
\hline & $\operatorname{Dose}^{3 /}$ & Pousio & Aveia-preta & Trigo & Nabo & Ervilhaca & Azevém \\
\hline Roçada & - & B $35 a^{*}$ & $\mathrm{~A} 11 \mathrm{~b}$ & A $15 b$ & $\mathrm{~A} 0 \mathrm{c}$ & $\mathrm{A} 0 \mathrm{c}$ & A 6 b \\
\hline Gly $^{1 /}$ & 720 & A $41 \mathrm{a}$ & $\mathrm{AB} 10 \mathrm{~b}$ & $\mathrm{~A} 12 \mathrm{~b}$ & $\mathrm{~A} 0 \mathrm{c}$ & $\mathrm{A} 0 \mathrm{c}$ & $\mathrm{A} 5 \mathrm{~b}$ \\
\hline Gly+2,4-D & $720+1005$ & D $8 \mathrm{a}$ & $\mathrm{C} 5 \mathrm{~b}$ & B $6 \mathrm{~b}$ & $\mathrm{~A} 0 \mathrm{c}$ & $\mathrm{A} 0 \mathrm{c}$ & $\mathrm{A} 6 \mathrm{~b}$ \\
\hline Gly $+2,4-\mathrm{D} /$ paraquat + diuron & $720+1005 / 200+100$ & E 2 a & $\mathrm{D} 0 \mathrm{~b}$ & $\mathrm{C} 0 \mathrm{~b}$ & $\mathrm{~A} 0 \mathrm{~b}$ & $\mathrm{~A} 0 \mathrm{~b}$ & $\mathrm{~B} 1 \mathrm{~b}$ \\
\hline $\mathrm{Gly}+\mathrm{Ch}^{2 /}$ & $720+80$ & $\mathrm{CD} 11 \mathrm{a}$ & $\mathrm{BC} 7 \mathrm{~b}$ & $\mathrm{C} 2 \mathrm{c}$ & $\mathrm{A} 0 \mathrm{~d}$ & $\mathrm{~A} 0 \mathrm{~d}$ & A 6 bc \\
\hline $\mathrm{Gly}+\mathrm{Chl} /$ paraquat+diuron & $720+80 / 200+100$ & C 13 a & $\mathrm{C} 4 \mathrm{~b}$ & $\mathrm{C} 2 \mathrm{bc}$ & $\mathrm{A} 0 \mathrm{c}$ & A $0 \mathrm{c}$ & B $0 \mathrm{c}$ \\
\hline CV $(\%)$ & & & & & & & \\
\hline
\end{tabular}

1/ glyphosate; ${ }^{2 /}$ chlorimuron-ethyl; ${ }^{3 /}$ Dose em g e.a ou g i.a ha ${ }^{-1}$.

* Letras maiúsculas semelhantes na coluna e letras minúsculas semelhantes na linha não diferem entre si pelo teste de DMS a $5 \%$. 


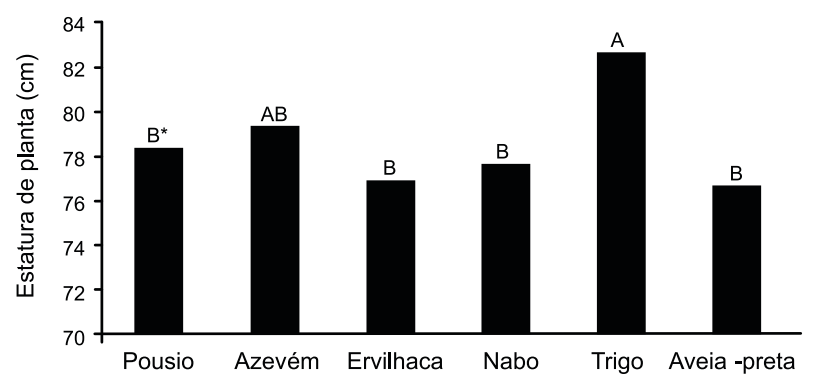

* Médias seguidas de mesma letra não diferem entre si pelo teste de Duncan a $5 \%$ de probabilidade.

Figura 1 - Estatura de planta de soja (cv. BMX Energia), em função das coberturas de inverno. Jaboticaba-RS, 2010/2011.

No tocante aos componentes da produtividade da soja, para as variáveis número de legumes por planta e número de grãos por legume não foi observado efeito significativo dos tratamentos sobre suas médias (Figura 2 e Tabela 4). Esses dados estão de acordo com os obtidos por Lima et al. (2009), que não observaram diferença no comportamento dessas variáveis quando da utilização de diferentes coberturas de inverno. No entanto, para o número de grãos por legume (Figura 2), constatou-se efeito das coberturas de inverno sobre essa variável, em que a soja após o trigo produziu menor número de grãos por legume, sendo inferior aos demais tratamentos, inclusive quando da comparação com a testemunha. A soja na sucessão do azevém, por sua vez, demonstrou os melhores indices para esse componente da produtividade; contudo, não se diferenciou, estatisticamente, dos tratamentos pousio, ervilhaca e aveia-preta.

Em relação ao peso de mil sementes (PMS), de maneira geral, os tratamentos que tiveram a ervilhaca como planta de cobertura associada ou não à utilização de herbicidas de modos de ação diferenciados ao glyphosate e em aplicação sequencial tiveram desempenho superior ao dos demais (Tabela 5). A partir desses resultados, pode-se inferir uma correlação direta do efeito supressor da cobertura de inverno com o desempenho produtivo da cultura. No entanto, os resultados demonstram de maneira geral que, para o efeito dos tratamentos utilizados em pré-dessecação, os herbicidas usados de forma associada e em aplicação sequencial resultaram em efeito superior no controle da buva e, consequentemente, no peso de mil sementes, quando da não utilização de herbicidas ou da utilização isolada do glyphosate.

Os resultados de produtividade de grãos da soja são apresentados na Tabela 6. Observa-se que no tratamento considerado como testemunha, tanto no inverno (pousio) como na présemeadura da soja (roçada), observou-se a menor produtividade de grãos, equivalente a $2.976 \mathrm{~kg} \mathrm{ha}^{-1}$. Desse modo, o percentual de redução de rendimento em relação à soja em sucessão ao azevém, tendo como tratamento de dessecação glyphosate + 2,4-D (maior produtividade de $4901 \mathrm{~kg} \mathrm{ha}^{-1}$ ), foi em torno de $60 \%$. Nesse contexto, ressalta-se a importância de um eficaz controle da buva antes do estabelecimento da cultura. Oliveira Neto et al. (2010) obtiveram resultados semelhantes ao trabalhar com a associação de glyphosate + 2,4-D para o controle de buva, antecedendo o cultivo da soja. Esses autores observaram incremento em torno de $44 \%$ na produtividade na área onde foi utilizada essa associação, quando comparado à testemunha.

Para o tratamento pousio no inverno com apenas glyphosate na dose de 720 g e.a ha ${ }^{-1}$ na dessecação pré-semeadura da soja, a redução da produtividade também foi acentuada em relação à dos demais tratamentos. Isso se deve à sobrevivência de plantas de buva na área, o que, segundo Oliveira Junior et al. (2006), modifica a qualidade da luz incidente sobre a cultura da soja, provocando o estiolamento da cultura e, posteriormente, a redução na produtividade de grãos. Constantin et al. (2009) observaram, ainda, estiolamento da cultura da

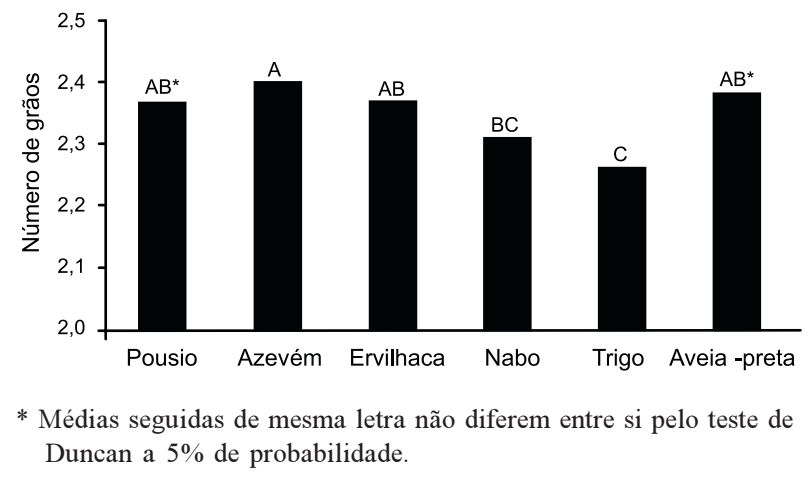

Figura 2 - Número de grãos por legume da soja (cv. BMX Energia), em função de coberturas de inverno. JaboticabaRS, 2010/2011. 
soja quando emergida antes da morte da cobertura vegetal, devido à busca por uma posição mais elevada no dossel.
A partir dos resultados observados na Tabela 6, é possivel inferir ainda que apenas a utilização de coberturas de inverno foi

Tabela 4 - Número de legumes por planta de soja, cv. BMX Energia, em função de coberturas de inverno e manejo da cobertura vegetal pré-semeadura da soja. Jaboticaba-RS, 2010/11

\begin{tabular}{|c|c|c|c|c|c|c|c|}
\hline \multirow{2}{*}{ Manejo } & \multicolumn{7}{|c|}{ Cobertura de inverno } \\
\hline & $\operatorname{Dose}^{3 / /}$ & Pousio & Aveia-preta & Trigo & Nabo & Ervilhaca & Azevém \\
\hline Roçada & - & $47,0^{\text {ns }}$ & $49,6^{\text {ns }}$ & $51,4^{\text {ns }}$ & $51,6^{\mathrm{ns}}$ & $53,5^{\text {ns }}$ & $56,4^{\text {ns }}$ \\
\hline Gly $^{1 /}$ & 720 & 45,2 & 53,3 & 50,8 & 51,1 & 53,7 & 51,0 \\
\hline Gly+2,4-D & $720+1005$ & 54,5 & 56,1 & 54,0 & 54,2 & 56,4 & 51,5 \\
\hline Gly $+2,4-\mathrm{D} /$ paraquat + diuron & $720+1005 / 200+100$ & 53,3 & 56,3 & 52,0 & 55,7 & 58,1 & 52,4 \\
\hline $\mathrm{Gly}+\mathrm{Chl}^{2 /}$ & $720+80$ & 56,4 & 54,7 & 105,8 & 52,6 & 52,8 & 51,8 \\
\hline $\mathrm{Gly}+\mathrm{Chl} /$ paraquat+diuron & $720+80 / 200+100$ & 51,1 & 54,6 & 54,9 & 50,0 & 56,1 & 55,7 \\
\hline CV (\%) & & & & & & & \\
\hline
\end{tabular}

1/ glyphosate; ${ }^{2 /}$ chlorimuron-ethyl; ${ }^{3 /}$ Dose em g e.a ou g i.a ha ${ }^{-1}$.

${ }^{\text {ns }}$ Médias nas linhas e nas colunas não diferem entre si pelo teste de DMS a 5\%.

Tabela 5 - Peso de mil sementes (PMS) da soja, cv. BMX Energia, em função de coberturas de inverno e manejo da cobertura vegetal pré-semeadura da soja. Jaboticaba-RS, 2010/11

\begin{tabular}{|c|c|c|c|c|c|c|c|}
\hline \multirow{2}{*}{ Manejo } & \multicolumn{7}{|c|}{ Cobertura de inverno } \\
\hline & $\operatorname{Dose}^{3 /}$ & Pousio & Aveia-preta & Trigo & Nabo & Ervilhaca & Azevém \\
\hline Roçada & - & A $17,0 b^{*}$ & B $16,50 \mathrm{~b}$ & $\mathrm{AB} 16,91 \mathrm{~b}$ & A 17,43 a & A 17,67 a & B $16,15 \mathrm{c}$ \\
\hline $\mathrm{Gly}^{1 / /}$ & 720 & $\mathrm{AB} 16,6 \mathrm{~b}$ & AB $16,85 \mathrm{a}$ & $\mathrm{AB} 17,13 \mathrm{a}$ & $\mathrm{B} 16,75 \mathrm{a}$ & A 17,03 a & A 16,74 a \\
\hline Gly+2,4-D & $720+1005$ & B $16,4 \mathrm{~b}$ & $\mathrm{AB} 16,80 \mathrm{ab}$ & $\mathrm{AB} 16,94 \mathrm{a}$ & $\mathrm{AB} 17,14 \mathrm{a}$ & A $16,62 \mathrm{ab}$ & $\mathrm{AB} 16,62 \mathrm{ab}$ \\
\hline Gly+2,4-D/paraquat+diuron & $720+1005 / 200+100$ & A 17,2 a & $\mathrm{AB} 16,77 \mathrm{~b}$ & A 17,26 a & A 17,39 a & A 16,92 a & AB $16,33 \mathrm{c}$ \\
\hline $\mathrm{Gly}+\mathrm{Chl}^{2} /$ & $720+80$ & B $16,3 \mathrm{~b}$ & $\mathrm{AB} 16,57 \mathrm{~b}$ & B $16,69 \mathrm{ab}$ & $\mathrm{AB} 17,11 \mathrm{a}$ & A $16,85 \mathrm{ab}$ & A $17,21 \mathrm{a}$ \\
\hline Gly $+\mathrm{Chl} /$ paraquat + diuron & $720+80 / 200+100$ & B $16,5 b$ & A 17,04 a & A $17,28 \mathrm{a}$ & A $17,51 \mathrm{a}$ & A 17,13 a & A 17,04 a \\
\hline CV $(\%)$ & & & & & 8 & & \\
\hline
\end{tabular}

1/ glyphosate; ${ }^{2 /}$ chlorimuron-ethyl; ${ }^{3 /}$ Dose em g e.a ou g i.a ha ${ }^{-1}$.

* Letras maiúsculas semelhantes na coluna e letras minúsculas semelhantes na linha não diferem entre si pelo teste de DMS a 5\%.

Tabela 6 - Produtividade da soja $\left(\mathrm{kg} \mathrm{ha}^{-1}\right)$, cv. BMX Energia, em função de coberturas de inverno e manejo da cobertura vegetal présemeadura da soja. Jaboticaba-RS, 2010/11

\begin{tabular}{|c|c|c|c|c|c|c|c|}
\hline \multirow{2}{*}{ Manejo } & \multicolumn{7}{|c|}{ Cobertura de inverno } \\
\hline & $\operatorname{Dose}^{3 /}$ & Pousio & Aveia-preta & Trigo & Nabo & Ervilhaca & Azevém \\
\hline Roçada & - & C $2976,0 \mathrm{~d}$ & C $3701,4 \mathrm{c}$ & C $3885,6 \mathrm{c}$ & C 3996,1 bc & B 4512,4 a & B $4220,3 \mathrm{ab}$ \\
\hline $\mathrm{Gly}^{1 /}$ & 720 & B $3723,8 \mathrm{c}$ & B 4404,6 a & B $4315,7 \mathrm{ab}$ & $\mathrm{C} 4052,2 \mathrm{~b}$ & B 4483,1 a & B 4408,2 a \\
\hline Gly+2,4-D & $720+1005$ & A 4358,6 b & A 4848,7 a & $\mathrm{AB} 4593,0 \mathrm{ab}$ & B 4414,7 b & B $4386,5 \mathrm{~b}$ & B $4406,7 \mathrm{~b}$ \\
\hline Gly $+2,4-D /$ paraquat+diuron & $720+1005 / 200+100$ & A $4519,8 \mathrm{c}$ & A 4759,8 bc & A $4712,3 \mathrm{ab}$ & A $4770,6 \mathrm{ab}$ & A $4854,4 \mathrm{ab}$ & A 4901,1 a \\
\hline $\mathrm{Gly}+\mathrm{Chl}^{2 /}$ & $720+80$ & A $4484,5 \mathrm{ab}$ & B $4446,1 \mathrm{ab}$ & A $4686,8 \mathrm{a}$ & A 4747,4 a & B $4347,0 \mathrm{~b}$ & B $4338,7 \mathrm{~b}$ \\
\hline Gly $+\mathrm{Chl} /$ paraquat + diuron & $720+80 / 200+100$ & A 4644,4 b & B $4385,5 \mathrm{~b}$ & A 4753,5 ab & B 4424,3 b & A 4912,1 a & A 4824,8 a \\
\hline CV $(\%)$ & & & & & & & \\
\hline
\end{tabular}

1/ glyphosate; ${ }^{2 /}$ chlorimuron-ethyl; ${ }^{3 /}$ Dose em g e.a ou g i.a ha ${ }^{-1}$.

* Letras maiúsculas semelhantes na coluna e letras minúsculas semelhantes na linha não diferem entre si pelo teste de DMS a 5\%. 
suficiente para garantir boa produtividade da cultura; no entanto, a dessecação das coberturas com herbicidas alternativos associados ao glyphosate na pré-semeadura da soja favoreceu o estabelecimento da cultura livre da presença de plantas daninhas e proporcionou incremento da produtividade de grãos.

Observou-se diferença significativa no desempenho do herbicida glyphosate isolado, quando comparado à sua utilização em associação com chlorimuron-ethyl ou 2,4-D, com aplicação sequencial de paraquat + diuron; isso ocorre porque as associações são capazes de garantir controle da buva resistente ao glyphosate e, em consequência, uma maior produtividade da cultura.

Assim, dada a importância do seu impacto na cultura da soja e a facilidade de disseminação que apresenta, torna-se fundamental eliminar plantas de $C$. bonariensis resistentes ao glyphosate. A ocorrência da resistência aos herbicidas e a magnitude que o caso da buva adquiriu ressaltam a importância da adoção de um sistema de manejo integrado de plantas daninhas na propriedade agrícola. A rotação de áreas de soja com milho não geneticamente modificado para resistência ao glyphosate, por exemplo, traz a opção de utilização de diversos mecanismos de ação herbicida, reduzindo a pressão de seleção imposta por um exclusivo mecanismo de ação, como no caso da soja geneticamente modificada, e o uso de glyphosate, de modo a garantir a sustentabilidade do sistema produtivo.

A utilização de coberturas de inverno, principalmente nabo e ervilhaca, é eficiente em suprimir a emergência e o desenvolvimento da buva. No entanto, é necessária a associação de glyphosate com herbicidas que possuem mecanismo de ação alternativo, como 2,4-D ou chlorimuron-ethyl, complementados com uma aplicação próxima à semeadura da cultura de um herbicida de contato, como paraquat+ diuron, visando reduzir a incidência de buva resistente a glyphosate e evitando, desse modo, comprometer a produtividade da soja.

\section{AGRADECIMENTOS}

À família Santi, em especial ao sr. Valdomiro Pigatto Santi e sr. Isaldo Ângelo
Dalbianco, pela concessão da área e pelo auxílio na condução do experimento. Aos alunos do curso de Agronomia André Luis Vian, Júnior Mello Damian e Sérgio Daniel Bona, pelo auxílio na aplicação dos tratamentos e na operação de colheita.

\section{LITERATURA CITADA}

BALBINOT JR., A. A.; BIALESKI, M.; BACKES, R. L. Épocas de manejo de plantas de cobertura do solo de inverno e incidência de plantas daninhas na cultura do milho. R. Agropec. Catarinense, v. 18, n. 3, p. 91-94, 2005.

BHOWMIK, P. C.; BEKECH, M. M. Horseweed (Conyza canadensis) seed production, emergence, and distribution in no-tillage and conventional tillage corn (Zea mays).

Agronomy, v. 1, n. 1, p. 67-71, 1993.

CONSTANTIN, J. et al. Sistemas de manejo de plantas daninhas no desenvolvimento e na produtividade da soja. Bragantia, v. 68, n. 1, p. 125-135, 2009.

CORREA, N. M. et al. Influência do tipo e da quantidade de resíduos vegetais na emergência de plantas daninhas.

Planta Daninha, v. 24, n. 2, p. 245-253, 2006.

DAUER, J. T. et al. Controlled experiments to predict horseweed (Conyza canadensis) dispersal distances. Weed Sci., v. 54, n. 3, p. 484-489, 2006.

\section{EMPRESA BRASILEIRA DE PESQUISA}

AGROPECUÁRIA - EMBRAPA. Sistema brasileiro de classificação de solos. 2.ed. Brasília: Embrapa Produção de Informação/Rio de Janeiro, Embrapa Solos, 2006. $412 \mathrm{p}$.

KISSMANN, K. G.; GROTH, D. Plantas infestantes e nocivas. 2.ed. São Paulo: Basf Brasileira, 1999. p. 978. Tomo II.

LIMA, E. V. et al. Características agronômicas, produtividade e qualidade fisiológica da soja "safrinha" sob semeadura direta, em função da cobertura vegetal e da calagem superficial. R. Bras. Sementes, v. 31, n. 1, p. $69-80,2009$

OLIVEIRA, M. R. et al. Efeito da palha e da mistura atrazine e metolachlor no controle de plantas daninhas na cultura do milho, em sistema de plantio direto. Pesq. Agropec. Bras., v. 36, n. 1, p. $37-41,2001$.

OLIVEIRA JUNIOR, R. S. et al. Interação entre sistemas de manejo e de controle de plantas daninhas em pós-emergência afetando o desenvolvimento e a produtividade da soja. Planta Daninha, v. 24, n. 4, p. 721-732, 2006. 
OLIVEIRANETO, A. M. et al. Estratégias de manejo de inverno e verão visando ao controle de Conyza bonariensis e Bidens pilosa. Planta Daninha, v. 28, p. 1107-1116, 2010. (Numero Especial)

PAUlA, J. M. et al. Manejo de Conyza bonariensis resistente ao herbicida glyphosate. Planta Daninha, v. 29, n. 1, p. 217-227, 2011.
VARGAS, L. et al. Buva (Conyza bonariensis) resistente ao glyphosate na região Sul do Brasil. Planta Daninha, v. 25, n. 3, p. 573-578, 2007.

ZHENG, D. et al. Cross-resistance of horseweed (Conyza canadensis) populations with three different ALS mutations. Pest. Manag. Sci., v.67, n. 12, p. 1486-1492, 2011. 